DOI:

http://dx.doi.org/10.15448/1983-4012.2018.1.31456

\title{
O PARADOXO DO PREFÁCIO GENERALIZADO
}

\author{
The Preface Paradox Generalized
}

Lucas Roisenberg Rodrigues *

Resumo: O paradoxo do prefácio é um presumido contraexemplo à tese de que a consistência é uma condição necessária da racionalidade ou justificação. $\mathrm{O}$ artigo visa desenvolver a ideia, na esteira de uma sugestão Earl Conee (2009), de que as presumidas crenças inconsistentes e racionais podem ser formadas a partir de fontes evidenciais radicalmente diferentes. A execução de tal tarefa está dividida em quatro partes. Na primeira delas, eu apresento sumariamente o paradoxo propriamente dito. Logo em seguida, eu apresento os outros exemplos: o evento, viagem de avião, encontro de colegas e memória parcial. Após isto, tento identificar a estrutura subjacente aos exemplos, e sugiro que a teoria da anulabilidade é uma ferramenta útil para pensar os contraexemplos. Por fim, ofereço uma análise diacrônica de um dos exemplos e tento reforçar a dificuldade de encontrar uma solução satisfatória para o problema.

Palavras-chave: Paradoxo do Prefácio; Inconsistência; Racionalidade; Justificação.

\begin{abstract}
The preface paradox is a presumed counterexample to the claim that consistency is a necessary condition for rationality or justification. This article develops the idea, first suggested by Earl Conee (2009), that the inconsistent and rational beliefs might be formed or based on very different kinds of evidence. This task will be executed in four parts. In the first one, I will briefly introduce and explain the preface paradox itself. Right after, I will present the other examples: the event, airplane, the meeting and partial memory. Then I will identify the common structure of all these examples, and will suggest that defeasibility theory is a useful tool for analyzing them. In the end, I will make a diachronic analysis of one example, and then show that is harder to solve the paradox than we usually think.
\end{abstract}

Keywords: Preface Paradox; Inconsistency; Rationality; Justification.

\footnotetext{
* Bacharel em Filosofia pela Universidade Federal do Rio Grande do Sul (UFRGS). Mestre e Doutor em Filosofia pela Pontifícia Universidade Católica do Rio Grande do Sul (PUCRS). Professor de Filosofia da Universidade Federal da Fronteira Sul (UFFS). E-mail para contato: lucasroisenberg@ gmail.com.
}

\begin{tabular}{|c|c|c|c|c|c|}
\hline intuitio & $\begin{array}{c}\text { ISSN } \\
1983-4012 \\
\end{array}$ & Porto Alegre & Vol.11 - $\mathrm{N}^{\mathrm{o}} .1$ & $\begin{array}{l}\text { Julho } \\
2018 \\
\end{array}$ & p. $07-18$ \\
\hline
\end{tabular}




\section{Introdução}

Suponha que um sujeito $S$ terminou de escrever um livro muito extenso e que cada proposição contida no livro expressa uma crença correspondente de seu autor. Por hipótese, cada uma das proposições do livro corresponde a um crença justificada de $S$, a qual é apoiada por um conjunto robusto de evidências. A justificação que $S$ tem para cada proposição no livro é boa e adequada, ainda que nenhuma evidência garanta a verdade da crença em questão. Afinal, somos todos falíveis e cognitivamente imperfeitos, e não queremos dizer que somente seres infalíveis possuem crenças justificadas. ${ }^{1}$

Pensemos agora sobre o livro um todo. Não é extremamente improvável que todas as crenças em questão sejam verdadeiras, se forem em número suficientemente elevado, independentes entre si e cada uma associada a um risco não nulo de erro? Ora, é verdade que não existe qualquer razão forte o suficiente para rejeitar qualquer uma das proposições individualmente; no entanto, quando $S$ considera o livro como um todo, isto é, a proposição que afirma serem verdadeiras todas as sentenças, é inclinado precisamente na direção contrária. O risco de erro e a falibilidade, negligenciável para cada crença individual, não pode ser ignorado para o todo. Alguma falsidade, cuja localização precisa desconhecemos, deve estar presente em algum lugar.

Não seria o caso, então, de julgar que é razoável para $S$ crer que alguma das crenças do livro deve ser falsa? Se é esta a conclusão que queremos extrair, então $S$ é claramente inconsistente: para cada proposição do livro, ele acredita que ela é verdadeira, e $S$ acredita que não é o caso que todas são verdadeiras (ou, equivalentemente, que existe alguma falsidade entre elas). Isto tudo não pode ser verdadeiro (e por isto a inconsistência): não é possível que cada proposição seja verdadeira e que alguma delas seja falsa. Ora, cada crença individual nos parece bem justificada e a conclusão de que nem todas são verdadeiras também. Não é razoável sugerir que $S$ deve abandonar qualquer uma das crenças individuais (qual delas e por que?), nem abandonar o livro inteiro, de uma só vez.

A estória que contamos alude ao conhecido paradoxo do prefácio. ${ }^{2}$ Este artigo é uma tentativa de desenvolver uma observação valiosa feita por Earl Conee a respeito do paradoxo do prefácio, de que "as crenças inconsistentes podem ser apoiadas por virtualmente qualquer tipo de evidência" (Conee, 2009: 654). Se a observação de Conee está correta, como penso ser o caso, então é pertinente perguntar pelo que torna possível a reunião destes diferentes casos.

\footnotetext{
${ }^{1}$ Partes deste texto foram retiradas de minha dissertação, (cf. Rodrigues, 2012), na qual discuto mais extensamente o paradoxo do prefácio e examino diferentes soluções do problema.

${ }^{2}$ O paradoxo original, formulado por Makinson (1965), dizia respeito a situação de um autor que escreve um livro acadêmico extenso e reconhece, no prefácio do mesmo, que alguma das proposições contidas no livro deve ser falsa (por esta razão o nome "paradoxo do prefácio").
}

\begin{tabular}{|c|c|l|l|l|l|}
\hline intuitio & $\begin{array}{c}\text { ISSN } \\
1983-4012\end{array}$ & Porto Alegre & Vol.11- $\mathrm{N}^{\circ} .1$ & $\begin{array}{l}\text { Julho } \\
2018\end{array}$ & p. 07-18 \\
\hline
\end{tabular}


Nas linhas que seguem, farei três coisas: (1) apresentarei outros exemplos semelhantes ao paradoxo do prefácio, que no entanto partem de fontes evidenciais distintas; ${ }^{3}$ (2) tentarei identificar a estrutura comum, a matriz geradora dos contraexemplos e (3) procurarei reforçar os exemplos mediante uma análise diacrônica de um dos exemplos.

\section{Outros Exemplos}

Conforme sugeri, existem outros exemplos estruturalmente idênticos ao paradoxo do prefácio, que envolvem fontes evidenciais distintas. A seguir, apresentarei alguns destes exemplos: o evento, a viagem de avião, o encontro de colegas e a memória parcial. Vejamos, agora, cada um deles.

\section{O EVENTO}

Suponha que você vai organizar um evento qualquer: uma festa, um casamento, um congresso, ou o que você quiser imaginar. Para organizar o evento, reunirá um determinado conjunto de pessoas em um mesmo lugar. Você envia um convite a cada um dos participantes e cada um deles confirma sua participação no evento. Como cada um dos convidados é uma pessoa cuja palavra é bastante respeitável, com um histórico bastante positivo de acertos, a confirmação de que ele irá participar no evento é evidência suficiente para crer que assim será. Afinal, formamos crenças racionais dessa forma o tempo todo, e muitas vezes a simples promessa de que uma pessoa irá fazer algo é razão suficiente para acreditar que a promessa irá cumprir-se.

Vamos supor que $A_{1}, A_{2}, \ldots, A_{n}$ é a lista de todos os convidados do evento. Como cada um deles confirmou que irá participar do evento, cada um dos elementos da seguinte lista de $n$ proposições é racional para você:

C: $A_{1}$ vai participar do evento, $A_{2}$ vai participar do evento, ..., $A_{n}$ vai participar do evento.

Até o presente momento, não parece haver nada de problemático. Porém, considere o seguinte raciocínio. A partir da totalidade das proposições do conjunto, pode-se inferir que:

C': $\mathrm{A}_{1}$ vai participar do evento \& $\mathrm{A}_{2}$ vai participar do evento, ..., \& $\mathrm{A}_{\mathrm{n}}$ vai participar do evento.

O problema torna-se mais contundente quando constatamos que o conjunto $\mathbf{C}$ pode ser tão extenso quanto quisermos, e quanto mais extenso for o conjunto, maior a probabilidade de que ao menos alguma

\footnotetext{
${ }^{3}$ Mais sobre o que me refiro quando falo em fontes evidenciais será tratado ao longo do artigo.
}

\begin{tabular}{|c|c|l|l|l|l|}
\hline intuitio & $\begin{array}{c}\text { ISSN } \\
1983-4012\end{array}$ & Porto Alegre & Vol.11- No.1 & $\begin{array}{l}\text { Julho } \\
2018\end{array}$ & p. 07-18 \\
\hline
\end{tabular}


das proposições individuais seja falsa. Afinal de contas, quanto mais gente estiver na lista, maior é a probabilidade de erro e maior nossa confiança de que alguém irá faltar.

Para exemplificar isto, vamos supor que lista conste inicialmente de três pessoas: $A_{1}, A_{2}$ e $A_{3}$. A lista poderia ser expandida e não parece haver nenhuma razão para negar que isto seja possível. Então digamos que uma quarta pessoa é acrescentada à lista e também uma quinta, uma sexta e assim indefinidamente. À medida que cresce a lista, maior torna-se a probabilidade de que alguém (que não sabemos quem é) não compareça ao evento; também, à medida que cresce a lista, mais forte torna-se a nossa razão para crer que alguém não comparecerá ao evento.

Ao longo dessa expansão, existirá um determinado momento em que seria racional sustentar que alguém não comparecerá ao evento. E se isto acontecesse, haveria razão para crer em cada um dos elementos de um conjunto inconsistente da seguinte forma:

$$
\mathrm{A}_{1}, \mathrm{~A}_{2}, \ldots, \mathrm{A}_{\mathrm{n}}, \neg\left(\mathrm{A}_{1} \& \mathrm{~A}_{2} \& \ldots \& \mathrm{~A}_{\mathrm{n}}\right)
$$

\section{A VIAGEM DE AVIÃO}

Você acaba de embarcar em um avião. Você sabe que viagens de avião são seguras e acredita, com boas razões, que após o término da viagem, chegará seguro em seu destino. Assim, você acredita racionalmente e com boas razões (ainda que não infalíveis) na seguinte proposição: quando todos os cuidados de segurança necessários são tomados, é racional acreditar que não irá acontecer um acidente de avião.

Entretanto, você sabe que mesmo os melhores cuidados não impedem que imprevistos ocasionalmente aconteçam. Certamente, você acredita que isto não vai acontecer com o seu avião. Se você acreditasse racionalmente que isto vai acontecer, não seria racional embarcar no avião (supondo-se, é claro, que você tenha o objetivo de manter-se vivo). Tampouco você acredita que qualquer viagem de avião em particular, quando conduzida em condições semelhantes à sua, resultará em um acidente. No entanto, você sabe que acidentes de avião acontecem e que alguns não resultam de falhas ou descuidos de segurança.

Vamos supor que o conjunto de viagens de avião no ano atual seja $\mathrm{V}_{1}, \mathrm{~V}_{2}, \ldots, \mathrm{V}_{\mathrm{n}}$. Por hipótese, você memorizou o conjunto de viagens de avião planejadas para o atual ano. Assim, você acredita racionalmente em cada uma das proposições do seguinte conjunto:

1. $V_{1}$ não vai resultar em um acidente, $V_{2}$ não vai resultar em um acidente, $\ldots, V_{n}$ não vai resultar em um acidente.

\begin{tabular}{|c|c|c|c|c|c|}
\hline intuitio & $\begin{array}{c}\text { ISSN } \\
1983-4012\end{array}$ & Porto Alegre & Vol.11 - $\mathrm{N}^{\mathrm{o}} .1$ & $\begin{array}{l}\text { Julho } \\
2018\end{array}$ & p. $07-18$ \\
\hline
\end{tabular}


Entretanto, você acredita racionalmente que algum avião vai sofrer um acidente em algum lugar do mundo no atual ano, mesmo quando todos os cuidados de segurança possíveis forem tomados. A probabilidade de que nenhum acidente aconteça, quando sabemos que aconteceram em todos os anos anteriores (vamos supor que tenha sido assim), é muito baixa. De fato, ela parece tão baixa (mesmo que não sejamos capazes de mensurá-la) que fornece uma boa razão para crer que ela de fato vai se realizar. Assim, você conclui que:

2. Não é caso que: $V_{1}$ não vai resultar em um acidente $\& V_{2}$ não vai resultar em um acidente, ..., \& $\mathrm{V}_{\mathrm{n}}$ não vai resultar em um acidente).

Entretanto, 1 é inconsistente com 2. Consequentemente, você acredita racionalmente em um conjunto de proposições inconsistentes entre si.

\section{ENCONTRO DE COLEGAS}

Considere agora outra situação. Imagine que Silva publicou um recente livro, por exemplo, um livro de história que contém diversas informações e asserções factuais. Cada proposição do livro foi checada pelos mais rigorosos métodos científicos e apoiada pelas melhores evidências disponíveis. Cada proposição contida no livro expressa uma crença racional de Silva.

Suponha que Silva encontrou o colega João e imediatamente começam a conversar. João é um historiador de renome e raramente engana-se em seus juízos, especialmente no que diz respeito à sua área de competência. Além do mais, ele é um destes raros tipos cuja honestidade está acima de qualquer suspeita - de fato, João é um caso praticamente incontestável de boa testemunha.

Ao longo da conversa, e para a surpresa de Silva, João afirma possuir consigo um documento histórico, descoberto em sua mais recente pesquisa, o qual mostra haver uma afirmação incorreta no último livro de Silva. Sem ter qualquer razão para duvidar do testemunho de João, ele imediatamente começa a conjecturar onde é que pode ter cometido algum erro. Não tendo menor ideia da localização do erro, curioso acerca da nova informação, esboça uma pergunta a este respeito. No entanto, antes que possa completá-la, a conversa é subitamente interrompida; João precisa despedir-se: um compromisso urgente o aguarda.

Após a despedida, Silva encontra-se convencido da veracidade do testemunho de João, ainda que lamente não ter tido tempo de obter mais informações. Contudo, imprevistos, interrupções deste tipo, não são apenas normais: são coisas que esperamos que aconteçam cedo ou tarde.

Assim, sua crença de que existe um erro no livro não parece irracional, pois tem como fundamento um testemunho confiável, do qual não há qualquer razão para duvidar. Formamos muitas

\begin{tabular}{|c|c|c|c|c|c|}
\hline intuitio & $\begin{array}{c}\text { ISSN } \\
1983-4012\end{array}$ & Porto Alegre & Vol.11- $\mathrm{N}^{\mathrm{o}} .1$ & $\begin{array}{l}\text { Julho } \\
2018\end{array}$ & p. 07-18 \\
\hline
\end{tabular}


crenças racionais desta forma, e o caso de Silva seria típico e não problemático, se não houvesse uma complicação adicional.

Suponha que o conjunto formado pelas proposições do livro é o seguinte: $\mathrm{P}_{1}, \mathrm{P}_{2}, \mathrm{P}_{3}, \ldots, \mathrm{P}_{\mathrm{n}}$. Suponha ainda que o testemunho de João pode ser reformulado da seguinte maneira: Existe uma proposição $\mathrm{P}_{\mathrm{i}}$ no livro, tal que $\mathrm{P}_{\mathrm{i}}$ é falsa. Como $\mathrm{P}_{1}, \mathrm{P}_{2}, \ldots, \mathrm{P}_{\mathrm{n}}$ são todas as proposições do livro, então o testemunho de João justifica ou autoriza Silva a crer que $\neg\left(\mathrm{P}_{1} \& \mathrm{P}_{2} \& \ldots \& \mathrm{P}_{\mathrm{n}}\right)$.

O testemunho de João é claramente inconsistente com a negação da conjunção, pois o conjunto formado por $\mathrm{P}_{1}, \mathrm{P}_{2}, \ldots, \mathrm{P}_{\mathrm{n}}, \neg\left(\mathrm{P}_{1} \& \mathrm{P}_{2} \& \ldots \& \mathrm{P}_{\mathrm{n}}\right)$ é inconsistente. Contudo, tanto a crença em cada uma das proposições do livro, como a crença no testemunho de João, são racionais. Assim, são possíveis crenças racionais e inconsistentes.

\section{MEMÓRIA PARCIAL}

Imagine que você escreveu um livro, tal que cada uma das proposições ali contidas seja racional ou justificada. Digamos que, em um determinado momento, enquanto você revisa o livro, descobre que existe uma proposição falsa. Imediatamente, você anota a observação em um pedaço de papel, para se lembrar dela mais tarde.

Alguns dias depois, você retoma o manuscrito. Contudo, você não pode ignorar algumas coisas: lembra-se de ter encontrado algum erro no livro, da sensação de desapontamento por ter encontrado um problema e de tê-lo anotado em um pedaço de papel. Todavia, você não consegue encontrar mais o pedaço de papel, que provavelmente se encontra perdido na bagunça de suas anotações.

Seria possível lembrar-se de ter encontrado um erro, sem lembrar-se de qual era o erro? Aparentemente sim, e nossa memória parece funcionar às vezes dessa forma: lembramo-nos de algo, mas não de todos os detalhes envolvidos. Por exemplo, posso lembrar que tenho um compromisso agendado para amanhã, mas não lembrar qual compromisso ou qual horário. Algo semelhante parece acontecer nesse caso.

Em vistas disso, podemos fazer a pergunta: a lembrança de ter encontrado e anotado um erro no livro, ainda que não consiga lembrar qual erro, é suficiente para justificar a crença de que existe alguma crença falsa no livro? Vamos supor que sim e tentar descobrir quais consequências podem ser tiradas dessa suposição.

Digamos que o conjunto de proposições do livro seja o conjunto de $n$ proposições: $\mathrm{P}_{1}, \mathrm{P}_{2}, \mathrm{P}_{3} \ldots, \mathrm{P}_{\mathrm{n}}$. Cada uma delas, por hipótese, é justificada ou racional. Porém, existe a evidência mnemômica de que alguma delas é falsa. Essa evidência justifica a crença de que $\neg\left(\mathrm{P}_{1} \& \mathrm{P}_{2} \& \ldots \& \mathrm{P}_{\mathrm{n}}\right)$. Ora, se $\mathrm{P}_{1}, \mathrm{P}_{2}, \mathrm{P}_{3} \ldots, \mathrm{P}_{\mathrm{n}}$

\begin{tabular}{|c|c|c|c|c|c|}
\hline intuitio & $\begin{array}{c}\text { ISSN } \\
1983-4012\end{array}$ & Porto Alegre & Vol.11- $\mathrm{N}^{\mathrm{o}} .1$ & $\begin{array}{l}\text { Julho } \\
2018\end{array}$ & p. 07-18 \\
\hline
\end{tabular}


são justificadas para um sujeito $S$ e $\neg\left(\mathrm{P}_{1} \& \mathrm{P}_{2} \& \ldots \& \mathrm{P}_{\mathrm{n}}\right)$ é justificado para $S$, então $S$ possui justificação para cada um dos elementos do seguinte conjunto:

$$
\mathrm{P}_{1}, \mathrm{P}_{2}, \mathrm{P}_{3}, \ldots, \mathrm{P}_{\mathrm{n}}, \neg\left(\mathrm{P}_{1} \& \mathrm{P}_{2} \& \ldots \& \mathrm{P}_{\mathrm{n}}\right)
$$

O conjunto acima é inconsistente. Assim, se as suposições que fizemos forem corretas, então é possível que sujeito possua um conjunto de crenças inconsistentes e racionais.

\section{Generalizando o Paradoxo do Prefácio}

É possível abstrair dos diferentes casos que vimos uma forma ou estrutura, que descrevemos a seguir. Existe um conjunto de crenças racionais $\mathrm{A}_{1}, \mathrm{~A}_{2}, \ldots, \mathrm{A}_{\mathrm{n}}$ para um sujeito $S$. O conjunto de evidências para as crenças pertencentes ao conjunto formado por $A_{1}, A_{2}, \ldots, A_{n}$ é o conjunto formado por $E_{1}, E_{2}, \ldots$, $E_{n}$. As evidências $A_{1}, A_{2}, \ldots, A_{n}$ são distintas e independentes entre si. Entretanto, existe uma evidência $A^{\prime}$ para $\neg\left(A_{1} \& A_{2} \& \ldots \& A_{n}\right)$. A' não faz parte de $E_{1}, E_{2}, \ldots, E_{n}$, nem é evidência para negar qualquer proposição de individualmente. Contudo, o conjunto formado por $A_{1}, A_{2}, \ldots, A_{n}, \neg\left(A_{1} \& A_{2} \& \ldots \& A_{n}\right)$ é um conjunto inconsistente. Assim, é racional para $S$ acreditar na seguinte proposição:

D: Existe uma proposição $A_{i}$, tal que $A_{i}$ é falsa e pertence ao conjunto $A_{1}, A_{2}, \ldots, A_{n}$.

A proposição $\mathbf{D}$ tem duas características relevantes: (i) a sua base evidencial; (ii) a sua forma.

Quanto à base evidencial, constatamos que D pode estar justificada a partir de diferentes fontes evidenciais. Pode partir de uma inferência indutiva, consistindo assim em uma projeção de erros passados no presente. Pode partir de certos fatos relativos à natureza da probabilidade e ao risco de erro: que a proposição "eu tenho alguma crença falsa" pode ter uma probabilidade muito baixa, tão baixa quanto quisermos. Por fim, D pode partir de uma evidência testemunhal ou até mesmo partir da memória.

Quanto à forma, D é uma generalização existencial, não a negação de uma conjunção de todos os $\mathrm{A}_{1}, \mathrm{~A}_{2}, \ldots, \mathrm{A}_{\mathrm{n}}$, nem a negação de qualquer uma das $\mathrm{A}_{1}, \mathrm{~A}_{2}, \ldots, \mathrm{A}_{\mathrm{n}}$. Essa generalização existencial é indeterminada, i.e., ela não permite identificar qual é a proposição falsa em questão, ou seja, ela não discrimina onde está o erro, contentando-se simplesmente em afirmar que existe algum. A indeterminação de $\mathbf{D}$ explica, em parte, por que não acontece o que é comum quando descobrimos alguma falha ou erro em um conjunto de crenças: normalmente rejeitamos a proposição, ou conjunto de proposições, que mais provavelmente é a fonte do erro ou engano. Nada disto, entretanto, aplica-se ao paradoxo do prefácio e similares.

\begin{tabular}{|c|c|l|l|l|l|}
\hline intuitio & $\begin{array}{c}\text { ISSN } \\
1983-4012\end{array}$ & Porto Alegre & Vol.11- $\mathrm{N}^{\mathrm{o}} .1$ & $\begin{array}{l}\text { Julho } \\
2018\end{array}$ & p. 07-18 \\
\hline
\end{tabular}


Essa parece ser a forma geral do problema, a matriz ou estrutura que pode ser repetida em uma infinidade de casos particulares. Todavia, devemos indagar: o que torna possível, ou, pelo menos, aparentemente possível, situações semelhantes a essa?

Uma explicação bastante natural e intuitiva tenta dar conta do fenômeno utilizando algumas ideias básicas sobre probabilidade. Supondo-se a independência probabilística entre as crenças individuais, e alguma versão da tese de que existe algum limiar probabilístico para a formação da crença racional, é bastante plausível afirmar que a probabilidade da crença na conjunção pode estar abaixo do limiar necessário para a racionalidade da crença. ${ }^{4}$ De acordo com essa explicação, a inferência de $A_{1}, A_{2}, \ldots, A_{n}$ para $\left(A_{1} \& A_{2} \& \ldots \& A_{n}\right)$ não transmite racionalidade ou justificação porque a probabilidade da conjunção ser verdadeira pode ser muito menor que a probabilidade de qualquer um de seus elementos individuais, supondo-se, é claro, a independência probabilística entre as crenças individuais. ${ }^{5}$ Mais especificamente, ao realizarmos a inferência, ao passarmos da premissa para a conclusão, aumentamos o risco de erro envolvido, tornamo-nos mais vulneráveis ao erro. Esse incremento no risco de erro pode ser tão elevado que uma situação como a seguinte eventualmente ocorre: um sujeito ter justificação para um conjunto de proposições, fazer uma inferência válida para sua respectiva conjunção, e, no entanto, perder justificação ao longo do processo. Isso é que alegadamente ocorre no paradoxo do prefácio.

É digno de nota que essa explicação não dá conta dos outros exemplos de que tratamos. Por exemplo, no caso do Encontro de Colegas, a alegação de que existe alguma proposição falsa não é resultado de uma inferência probabilística. Afinal, a evidência para a crença de que alguma das proposições individuais é falsa não é probabilística, muito menos indutiva; é uma evidência testemunhal que, por qualquer critério razoável, seria considerada uma boa evidência justificadora.

Em vista disto, tentaremos encontrar uma maneira de compreender o problema que não inclua o caráter específico da justificação que o sujeito $S$ tem para crer que $\neg\left(\mathrm{A}_{1} \& \mathrm{~A}_{2} \& \ldots \& \mathrm{~A}_{\mathrm{n}}\right)$. Uma ferramenta útil para tal fim pode ser dada pela teoria da anulabilidade.

É um fato conhecido que muitas vezes a justificação que temos para uma determinada crença pode ser anulada ou revogada por uma informação adicional. A melhor teoria que visa explicar ou dar conta de tal fenômeno é conhecida como teoria da anulabilidade (Defeasability Theory). Penso que alguma luz é lançada sobre o paradoxo do prefácio, e sobre a estrutura subjacente relevante, quando examinamos a questão empregando os conceitos da teoria da anulabilidade.

O conceito de anulador requer alguns esclarecimentos. Digamos que um sujeito $S$ qualquer possua uma crença justificada de que P. D é um anulador de P se e somente se a seguinte condição for satisfeita:

\footnotetext{
${ }^{4}$ Agradeço ao André Neiva por ter chamado minha atenção para este ponto.

${ }^{5}$ Quando A e B são independentes entre si, $\operatorname{pr}(\mathrm{A} \& \mathrm{~B})=\operatorname{pr}(\mathrm{A}) \times \operatorname{pr}(\mathrm{B})$. Por exemplo, digamos que $\operatorname{pr}(\mathrm{A})=0,5$ e $\operatorname{pr}(\mathrm{B})=0,5$ e que A e B são probabilisticamente independentes. Neste caso, $\operatorname{pr}(\mathrm{A} \& \mathrm{~B})=0,25$.
}

\begin{tabular}{|c|c|l|l|l|l|}
\hline intuitio & $\begin{array}{c}\text { ISSN } \\
1983-4012\end{array}$ & Porto Alegre & Vol.11 $-\mathrm{N}^{\mathrm{o}} .1$ & $\begin{array}{l}\text { Julho } \\
2018\end{array}$ & p. 07-18 \\
\hline
\end{tabular}


se $S$ viesse a ter justificação para crer que D, então $S$ não teria justificação para crer que P. É dessa forma que o conceito tem sido definido pela maior parte dos teóricos anulabilistas.

É praxe, seguindo Pollock (1983), distinguir entre dois tipos básicos de anuladores: anulador evidencial (undercutting defeater) e anulador refutador (rebutting defeater). Uma proposição $\mathrm{D}_{1}$ é um anulador refutador de $\mathrm{P}$ se, e somente se, $\mathrm{D}_{1}$ anula a justificação para $\mathrm{P}$ e apoia a negação de $\mathrm{P}$. Uma proposição $\mathrm{D}_{2}$ é um anulador evidencial de $\mathrm{P}$ se, e somente se, $\mathrm{D}_{2}$ anula a justificação para $\mathrm{P}$, mas não apoia a negação de $P$.

Um contraste entre duas situações ilustra os conceitos de que tratamos. Suponhamos que eu creia que estou vendo um objeto vermelho com base nas minhas evidências perceptuais. Se eu adquirisse a informação de que o objeto é iluminado por uma luz vermelha, que faria ele parecer vermelho, eu perderia a justificação, que eu tinha antes da aquisição da nova informação, de que o objeto é vermelho. A minha justificação é anulada ou derrotada. Todavia, eu não adquiri justificação para crer que o objeto é vermelho, pois ainda poderia ser o caso, dado tudo o que eu sei, que o objeto é vermelho e iluminado por uma luz vermelha. O anulador "o objeto é iluminado por uma luz vermelha" funciona como um anulador evidencial, porém não como um anulador derrotador.

Comparemos a situação inicial com outra, levemente modificada. Suponha que eu adquiro a informação de que o objeto é branco e iluminado por uma luz vermelha. Neste segundo caso, o anulador “o objeto é branco e iluminado por uma luz vermelha" não meramente cancela a justificação inicial para a crença de que o objeto é vermelho; o anulador justifica a contraditória, qual seja, a crença de que o objeto não é vermelho.

Até agora tratamos da relação de anulabilidade como uma relação entre duas proposições. Todavia, nada impede que possamos falar da anulabilidade como uma relação entre dois conjuntos quaisquer de crenças. Assim, podemos dizer, por exemplo, que as crenças de que $\mathrm{P}$ e de que $\mathrm{P} \rightarrow \mathrm{Q}$ anulam conjuntamente a justificação da crença de que $\neg \mathrm{Q}$.

Essas constatações nos levam a tentar dar outra abordagem para o problema. Mais uma vez, o conceito de anulador é uma ferramenta útil. Usaremos o exemplo do paradoxo do prefácio original, mas o mesmo raciocínio deve ser aplicado às outras variações do paradoxo. Temos algo mais ou menos assim: por um lado, "existe alguma proposição falsa no livro" não parece anular a justificação para qualquer uma das proposições individuais do livro, ou mesmo a justificação para todas delas. Por outro lado, a totalidade das proposições individuais também não parece anular a justificação da negação de sua respectiva conjunção.

Todavia, a justificação para a crença na negação da conjunção parece muito boa e poderia provir de diferentes fontes evidenciais - constatação que fortalece a tese de que a negação da conjunção pode ser justificada. Ao mesmo tempo, as proposições individuais do livro parecem bem justificadas, ainda que a

\begin{tabular}{|c|c|l|l|l|l|}
\hline intuitio & $\begin{array}{c}\text { ISSN } \\
1983-4012\end{array}$ & Porto Alegre & Vol.11- $\mathrm{N}^{\mathrm{o}} .1$ & $\begin{array}{l}\text { Julho } \\
2018\end{array}$ & p. 07-18 \\
\hline
\end{tabular}


justificação seja falível. Como não sabemos qual dos corpos evidenciais deve ter prioridade sobre o outro, abre-se a possibilidade de que eles sejam, de alguma forma, racionais, e que, não tendo como racionalmente abrir mão de nenhum, um sujeito racional deve simplesmente aceitar ambos e a inconsistência que os acompanha.

Normalmente, quando descobrimos uma inconsistência em um conjunto de crenças que previamente admitíamos, temos uma ideia ou pista de como resolver a inconsistência: alguma das proposições anteriormente admitidas nos parece mais apropriada para ser abandonada, ou mesmo o conjunto como um todo nos parece digno de rejeição ou suspeição de juízo. É precisamente esta possibilidade que é excluída pela natureza da evidência inespecífica. O paradoxo surge porque a natureza inespecífica da evidência nos coloca em um impasse e não vemos maneira de restaurar a consistência que seja intelectualmente satisfatória.

\section{Uma Análise Diacrônica: Reforçando o Caso}

A situação levantada pelo paradoxo do prefácio e similares também pode ser apresentada em uma perspectiva diacrônica, isto é, que leva em consideração a aquisição de evidências ao longo da passagem do tempo. Esta entende o problema como dizendo respeito a como um agente deve modificar suas crenças em função da aquisição de novas informações. A perspectiva diacrônica é particularmente adequada para dar forma a um dos exemplos que vimos: o caso do encontra de colegas.

Qual deveria ser a atitude doxástica de Silva após ouvir o testemunho, e como esta nova informação deve ser integrada em seu sistema de crenças? Existem algumas alternativas de revisão disponíveis, que preservam a consistência do sistema de crenças de Silva. O autor poderia, por exemplo, manter a crença inicial em cada proposição individual do livro e então inferir que João deve estar equivocado.

A dificuldade óbvia aqui é que parece haver um excesso de dogmatismo. Silva não reconhece a própria falibilidade, isto é, que algum erro é possível, apesar dos seus melhores esforços? Não é João uma testemunha fidedigna, talvez um autor mais competente que o próprio Silva? Se previamente é reconhecido que algum erro é possível, e em momento posterior nos deparamos com uma evidência testemunhal de que tal erro de fato aconteceu, apenas o apego cego às próprias crenças explica a rejeição do testemunho de João. O único motivo para rejeitar o testemunho é precisamente que entra em conflito com as crenças individuais expressas no livro.

O curioso aqui é que, com pequenas alterações do exemplo, que em nada afetam o seu espírito e a lição que dele tiramos, poderíamos tornar a evidência testemunhal ainda mais forte e contundente. Suponhamos, por exemplo, que João é muito competente na área de que trata o livro, mais competente que

\begin{tabular}{|c|c|c|c|c|c|}
\hline intuitio & $\begin{array}{c}\text { ISSN } \\
1983-4012\end{array}$ & Porto Alegre & Vol.11- $\mathrm{N}^{\mathrm{o}} .1$ & $\begin{array}{l}\text { Julho } \\
2018\end{array}$ & p. 07-18 \\
\hline
\end{tabular}


o próprio Silva. E se isto ainda não é suficiente, vamos imaginar que uma multidão de outros experts, todos muito competentes, asserem que um, e apenas um, erro foi encontrado no livro, e que todos concordam quanto à localização precisa deste erro no corpo do livro, ainda que nenhum deles informe qual é a proposição falsa em questão. Nesta última situação, qualquer inclinação para a recusa do testemunho foi devidamente neutralizada. A única opção razoável, frente à aquisição das novas evidências, parece ser a formação da crença de que algum erro está presente no livro.

Se desejamos preservar a consistência do autor, só há uma alternativa: Silva deve revisar as crenças contidas no livro. Uma hipótese seria ele revisar todas as crenças do livro. Esta alternativa parece drástica e exagerada: rejeitar todas as crenças presentes livro - e vamos supor que elas são muito extensas e independentes entre si - apenas porque temos razão para acreditar que alguma delas é falsa?! Não apenas a reação esboçada aqui é inadequada, como também, se estivesse correta, deveria, por uma questão de paridade, estender-se para qualquer indivíduo falível que reflete sobre o seu sistema de crenças como um todo.

Vamos imaginar um sujeito que, tendo em mente a sua vida cognitiva como um todo, extrai a conclusão de que alguma crença, entre a infinidade que povoa o seu sistema doxástico, deve ser falsa. O sujeito em questão não tem qualquer razão para pensar que esta ou aquela crença individual deve ser falsa: apenas sabe que é falível e que, levando tudo em consideração, é razoável esperar que não esteja correto em tudo o que acredita. Assim como seria irrazoável esperar que um sujeito descartasse todas as suas crenças porque alguma delas (que não sabe qual é) deve ser falsa, também deveria o mesmo ser dito mutatis mutandis para Silva e seu livro.

Por fim, podemos modificar um pouco mais ainda o exemplo, de tal forma que a possibilidade de revisão global é devidamente descartada. Vamos supor que o expert, ou a multidão de experts, se assim preferimos, assere que existe apenas um erro contido no livro, e que todas as demais proposições são verdadeiras. Se este é o conteúdo do testemunho, então obviamente recusar o livro como um todo, em razão da aquisição da nova informação, não será razoável. Neste caso, o abandono de todas as proposições é incoerente com a informação recém-adquirida.

Rejeitar o livro como um todo não é, portanto, uma opção viável.

Bem, que alternativa resta? Só resta uma: rejeitar alguma crença individual. No entanto, não há qualquer razão para privilegiar qualquer proposição individual contida no livro. A evidência, conforme salientamos, é indeterminada e aberta. Nenhum motivo sugere que alguma crença é pior ou melhor que outra. Escolher uma em detrimento de qualquer outra seria um ato de suprema arbitrariedade. Optar aleatoriamente por alguma delas não poderia ser uma maneira racional de atualizar seu sistema face à aquisição de novas evidências.

\begin{tabular}{|c|c|l|l|l|l|}
\hline intuitio & $\begin{array}{c}\text { ISSN } \\
1983-4012\end{array}$ & Porto Alegre & Vol.11- $\mathrm{N}^{\mathrm{o}} .1$ & $\begin{array}{l}\text { Julho } \\
2018\end{array}$ & p. 07-18 \\
\hline
\end{tabular}


Nenhuma das revisões doxásticas preservadoras da inconsistência parece viável, e diferentes exemplos podem ser produzidos, que visam estabelecer a inconsistência baseada em fontes evidenciais distintas. Todas estas considerações sugerem que um caso forte, talvez mais do que as reflexões sobre o paradoxo têm sugerido, pode ser produzido.

\section{Conclusão}

O que fizemos até agora foi tentar desenvolver a sugestão elaborada por Conee. Para tanto, identificamos diferentes casos e sugerimos uma estrutura abstrata, que pode ser derivada dos exemplos. A lição a ser tirada do que vimos, é que o paradoxo do prefácio indica um problema de impacto geral sobre a nossa concepção de racionalidade.

A possibilidade de criar muitos exemplos estruturalmente idênticos a partir de fontes evidenciais de natureza completamente distinta é um fenômeno curioso, que exige alguma explicação. O presente artigo foi apenas uma tentativa de iniciar um movimento nesta direção.

\section{Referências}

CONEE, E. A. The Preface Paradox. In: DANCY, J.; SOSA, E.; STEUP, M. (Eds.). Companion to Epistemology, 2nd ed. Malden, MA: Wiley-Blackwell, 2009, p. 604-605.

MAKINSON, D. C. The Paradox of The Preface. Analysis, v. 25, n. 6, p. 205-207, 1965.

POLLOCK, J. L. Epistemology and Probability. Synthese, v. 55, n. 2, p. 231-252, 1983.

RODRIGUES, Lucas Roisenberg. Inconsistência e Racionalidade: uma introdução ao paradoxo do prefácio, 2012, 73 páginas. Dissertação de Mestrado (Mestrado em Filosofia) - Pontifícia Universidade Católica Do Rio Grande Do Sul, Porto Alegre, 2012.

\begin{tabular}{|c|c|l|l|l|l|}
\hline intuitio & $\begin{array}{c}\text { ISSN } \\
1983-4012\end{array}$ & Porto Alegre & Vol.11- $\mathrm{N}^{\circ} .1$ & $\begin{array}{l}\text { Julho } \\
2018\end{array}$ & p. 07-18 \\
\hline
\end{tabular}

